\title{
Behavior in Simulated Soil of Recycled Expanded Polystyrene/Waste Cotton Composites
}

\author{
Cleide Borsoi ${ }^{a}$, Karina H. Berwig ${ }^{\mathrm{b}}$, Lisete C. Scienzac, Bárbara C. D. A. Zoppas ${ }^{\mathrm{d}}$,
}

Rosmary N. Brandalise ${ }^{a, b}$, Ademir J. Zattera ${ }^{\text {a* }}$

\author{
a Postgraduate Program in Engineering Processes and Technologies - PGEPROTEC, Exact Science and \\ Technology Center - CCET, Caxias do Sul University - UCS, CEP 95070-560, Caxias do Sul, RS, Brazil \\ ${ }^{b}$ Laboratory of Polymers - LPOL, Caxias do Sul University - UCS, Caxias do Sul, RS, Brazil \\ ${ }^{c}$ Laboratory of Corrosion and Surface Protection - LCOR, Caxias do Sul University - UCS, \\ Caxias do Sul, RS, Brazil \\ ${ }^{\mathrm{L} L a b o r a t o r y}$ of Medical Mycology, Health Sciences Center, Caxias do Sul University - UCS, \\ Caxias do Sul, RS, Brazil
}

Received: March 27, 2013; Revised: September 6, 2013

\begin{abstract}
Composites consisting of waste cotton yarn (CF) from the textile industry and postconsumer expanded polystyrene (EPS) was followed during 90 days of exposure in simulated soil. The mechanical properties, morphologies and chemical natures of the composites were determined before and after exposure in simulated soil. The composites were made using a single-screw extrusion, a twin-screw extrusion and injection molding. The composites showed an increase of the mechanical properties nearly $50 \%$ in relation to the recycled expanded polystyrene (rEPS). After exposure in simulated soil the composites presented losses of mechanical properties. Evidence of the oxidation of the samples was demonstrated by the increase in the values of the carbonyl index after 30 days of exposure in simulated soil. Changes in the color of the surface of the sample were observed after 90 days of exposure and are due to the fungi and bacteria colonization on the surface.
\end{abstract}

Keywords: composites, recycled expanded polystyrene, waste cotton yarn, simulated soil

\section{Introduction}

The use of raw materials from renewable resources has attracted academic and technological interest because of its great potential to replace materials such as fiberglass, which is traditionally used in the manufacture of composites. Brazil, which is one of the most bio-diverse countries on the planet, ranks high in the production of vegetable fibers, such as sisal, ramie, jute, and cotton, among others ${ }^{1}$. In addition to being a good economic practice, the use of natural fibers can also reduce the use of products are difficult to decompose ${ }^{2,3}$.

The use of vegetable fibers as a reinforcement in composite materials boasts a number of advantages: a great potential to improve the performance of the polymers in technological applications ${ }^{4,5}$, a lessening of the environmental impact of its production ${ }^{6}$, relatively low costs, the abundance of such fibers, and the potential biodegradability under suitable environmental conditions $s^{4,5}$. The incorporation of vegetable fibers as a reinforcement in thermoplastics has been studied and has been found to increase the modulus of elasticity and the mechanical strength, reduce the weight of the final product, and change the degradation characteristics of the composite ${ }^{7}$. The use of vegetable fibers combines good mechanical properties with lower densities and good dimensional stability ${ }^{8}$.

Vegetable fibers are hydrophilic and usually incompatible with hydrophobic polymeric matrices 9 . To overcome this problem, treatment of the fibers and/or the

*e-mail: ajzatter@ucs.br use of coupling agents whose function is to increase the interaction between the matrix and the reinforcement, is required. These solutions allow for the efficient wetting of the fiber-matrix, improving the adhesion between the reinforcement and the matrix ${ }^{10}$. The incompatibility of the components is responsible for the low adherence in the fiber/ matrix interface and the low degree of dispersion of the fibers, which is detrimental to the mechanical properties of these materials ${ }^{11}$; thus, the incorporation of a coupling agent or an appropriate treatment of the fibers is often required. The most commonly used coupling agent in composites is a polyolefin grafted with maleic anhydride ${ }^{6}$.

Composites produced with vegetable fibers may produce composites that, after their useful life, exhibit the same degradation behavior as the vegetable fibers themselves because the fibers are considered a biodegradable load. When fibers are added to inert polymers, the inert polymers will be preferentially consumed; however, when fibers are used in biodegradable matrix composites, the fibers will act to slow the process of biological degradation, according to the studies reported by Harnnecker et al. ${ }^{12}$. Stromberg and Karlsson ${ }^{13}$ evaluated the changes in the properties of three separate composites, polypropylene (PP)/wood flour, recycled PP/cellulose and poly(lactic acid) (PLA)/wood flour, which were exposed to a mixture of microorganisms to evaluate the biodegradation of the materials. They found that the degradation of wood composites occurred as was 
expected because cellulose is a source of nutrition for the microorganisms. The formation of a biofilm occurred in all of the composites, including the composite with PP, which is an inert polymer. This was thought to have occurred because the cellulose fibers absorb more water, which facilitates colonization. Harnnecker et al. ${ }^{12}$ evaluated the behavior of a composite of curaua fiber in a matrix composed of a biodegradable, aliphatic-aromatic co-polyester and poly(lactic acid), called BP. With respect to biodegradation in simulated soil, the authors found that the incorporation of the fibers increased the water absorption, whereas the presence of maleic anhydride (MA- $g$-PP) reduced the level of water absorption. They related the presence of MA- $g$-PP and curaua fiber with the residual mass after 210 days of exposure in simulated soil and determined that $68 \%$ of the sample with curaua fiber and MA- $g$-PP remained, while only $26 \%$ of the pure BP sample remained.

The objective of this study is to evaluate the behavior of the composites with residue of cotton yarn (cotton fiber), a coupling agent (maleic anhydride) and recycled expanded polystyrene in simulated soil. The mechanical, chemical natures, and morphological properties of the composites were evaluated by tensile strength, FTIR, OM and SEM.

\section{Experimental}

\subsection{Material}

The cotton fibers were obtained from Indústria Têxtil H. Milagre in Farroupilha City, Rio Grande do Sul, Brazil. The cotton fibers used in this study originated from residues from the manufacture of fabrics in weaving machines. The postconsumer expanded polystyrene (EPS), supplied by ARCS (Association of Recyclers of Caxias do Sul) in Rio Grande do Sul, Brazil, possessed a melt flow index of $17 \mathrm{~g} / 10 \mathrm{~min}\left(200^{\circ} \mathrm{C}, 5 \mathrm{~kg}\right)$ and an average molecular weight of $195.041 \mathrm{~g} . \mathrm{mol}^{-1}$. The coupling agent used was maleic anhydride grafting polystyrene - poly (styrene-co-maleic anhydride), supplied by Sartomer Company, in Exton, Pennsylvania, United States. The coupling agent possessed an acid number of $281 \mathrm{mg} \mathrm{KOH} / \mathrm{g}$ and was composed of $25 \%$ maleic anhydride groups.

\subsection{Preparation of fiber}

The cotton waste, included in the form of yarn and identified in this study as cotton fiber, was segmented into pieces that were $25 \mathrm{~mm}$ long pieces. The fibers were washed by immersion in distilled water for $1 \mathrm{~h}$ at $25^{\circ} \mathrm{C}$ and were subsequently oven dried for $24 \mathrm{~h}$ at $70{ }^{\circ} \mathrm{C}$.

\subsection{Preparation of composites}

The postconsumer EPS used in this study was previously subjected to a degassing process, which was involved a single-unit piece of equipment consisting of a mill coupled to a heated endless screw; the degassing process followed the procedure previously described by Borsoi et al. ${ }^{14}$.

To obtain the composites, the polymer matrix and the cotton fibers were premixed in a single-screw extruder (Seibt model ES35FR) at a screw speed of $40 \mathrm{rpm}$. The temperatures at the different heating zones varied according to the following profile: 140,160 and $180^{\circ} \mathrm{C}$. The composites were then ground in a knife mill (Primotenica, model 1001) and dried in an oven for $12 \mathrm{~h}$ at $70{ }^{\circ} \mathrm{C}$. The resulting material was processed in a co-rotating twin-screw extruder with $\mathrm{L} / \mathrm{D}=32$ and $\mathrm{D}=20 \mathrm{~mm}(\mathrm{MH}$ Equipamentos, model COR 20-32-LAB) at a screw rotation speed of $200 \mathrm{rpm}$. The extruder had 8 heating zones with the following profile: $115,150,185,185,180,175,175$ and $170{ }^{\circ} \mathrm{C}$. The composites were then dried and fabricated by injection molding (Himaco Hidráulicos e Máquinas Ltda., model LHS 150-80) with the following temperature profile: 150,165 and $180^{\circ} \mathrm{C}$. The screw speed was $100 \mathrm{rpm}$, and the mold temperature was approximately $20^{\circ} \mathrm{C}$.

The identities of the composites are shown in Table 1. The formulations were developed with $20 \mathrm{wt} \%$ cotton fiber and $2 \mathrm{wt} \%$ coupling agent.

\subsection{Behavior in the simulated soil}

Evaluation behavior in simulated soil were performed as adapted from ASTM G160-03 ${ }^{15}$, using equal parts soil, horse manure and sand. The simulated soil was left to age for 4 months at ambient temperature and humidity. The $\mathrm{pH}$ and soil moisture content were monitored every 15 days, and the soil temperature was checked daily during the experiment. The simulated soil, after the 4 month maturation period, was brought to the Laboratory of Phito-pathology, Caxias do Sul University, to identify the microorganisms present in the soil. From this analysis, we identified fungi (Aspergillus spp, Penicillium spp, Verticillium spp, Fusarium spp, Mucor spp, Trichoderma spp) and bacteria, which allowed us to conduct the continuity test.

After maturation of the soil, the composites samples were buried in the soil and were allowed to degrade for periods of 30, 60 and 90 days in a greenhouse constructed for this experiment. After each exposure period, the samples were removed from the soil, washed with distilled water to remove the excess soil adhered to the surface, dried with absorbent paper, and then maintained in a desiccator until analysis.

\subsection{Sample characterization}

Tensile tests were carried out in a universal testing machine, the EMIC DL 2000, in accordance with ASTM D $638-10^{16}$ at a speed of $5 \mathrm{~mm} \cdot \mathrm{min}^{-1}$. The morphologies of the samples were first examined with an optical microscope (OM) using a Nikon brand, model Epiphot 200. The morphological characterization was performed with a JEOL JSM 6060 scanning electron microscope (SEM) at

Table 1. Identification and composition of the samples.

\begin{tabular}{lccc}
\hline \multicolumn{1}{c}{ Sample } & $\begin{array}{c}\text { rEPS } \\
(\mathbf{w t} \%)\end{array}$ & $\begin{array}{c}\text { CF } \\
(\mathbf{w t} \%)\end{array}$ & $\begin{array}{c}\text { AA } \\
(\mathbf{w t} \%)\end{array}$ \\
\hline rEPS & 100 & 0 & 0 \\
rEPS/2AA & 98 & 0 & 2 \\
rEPS/20CF & 80 & 20 & 0 \\
rEPS/20CF/2AA & 78 & 20 & 2 \\
\hline
\end{tabular}

rEPS - recycled expanded polystyrene; $\mathrm{CF}$ - cotton fiber (residues from weaving machines); AA - coupling agent (MA-g-PS). 
an accelerating voltage of $15 \mathrm{kV}$. The surfaces were coated with a thin layer of gold before SEM analysis. Fourier transform infrared spectroscopy (FTIR) was performed with attenuated total reflectance (ATR) using an IS10 Thermo Scientific Nicolet spectrometer with an analytical range of 4000 to $400 \mathrm{~cm}^{-1}$. The carbonyl index was evaluated as the ratio of the area of the peak at $1722 \mathrm{~cm}^{-1}\left(\mathrm{~A}_{1}\right)$ and the area of the peak at $1600 \mathrm{~cm}^{-1}\left(\mathrm{~A}_{2}\right)(\mathrm{C}-\mathrm{H}$ stretch$)$, which is the band that remained unchanged during the degradation ${ }^{17,18}$.

Carbonyl index $=\mathrm{A}_{1} / \mathrm{A}_{2}$

After the exposure period, the samples were washed in distilled water to remove residual soil from the surface of the composites, as specified by ASTM G160-03 ${ }^{15}$. This waste water was stored in sterile flasks for further analyses, such as the identification of fungi and bacteria from the soil. Phytosanitary diagnostics were performed in the Laboratory of Mycology of Caxias do Sul University.

\section{Results and Discussion}

The measured mechanical properties of the composites, with and without the coupling agent, are compared with the mechanical properties of the pure polymer samples before and after exposure in the soil in Figure 1.

The addition of cotton fiber promoted a $57 \%$ increase in the tensile strength (Figure 1a) of the sample rEPS/20CF compared to the pure matrix (rEPS), which indicates that the cotton fiber acts as load reinforcement and improves the mechanical properties of the material. Similar results were observed by Borsoi et al. ${ }^{19}$ in studies with cotton fibers. The effect of the coupling agent was not significant in this the initial evaluation.

Decreases of $11 \%$ and $28 \%$ in the tensile strength of the samples without cotton fibers were observed for rEPS and
rEPS/AA2, respectively, and are related to the exposure in the simulated soil. A greater reduction of the tensile strength of the composite with the coupling agent could be due to the use of peroxide as a reaction initiator in the graphitizing of maleic anhydride; residues from this process may act to promote the degradation of the polymeric matrix ${ }^{20,21}$.

Decreases of $10 \%$ and $7 \%$ were observed in the tensile strength of the rEPS/20CF sample and the rEPS/20CF/2AA sample, respectively, after exposure for 90 days in the simulated soil. The low level of reduction of the tensile strength found in the rEPS/20CF/2AA sample is due to the use of the coupling agent, which minimizes the water absorption of the fiber in the composite; water absorption is responsible for decreasing the mechanical properties ${ }^{22,23}$. When water penetrates into the composite, it results in the swelling of the vegetable fibers, which produces fractures in the matrix that allow increased diffusion of water into the composites, thus deteriorating the fiber/matrix interface and decreasing the mechanical properties.

Figure $1 \mathrm{~b}$ revealed the same trends in sample properties with respect to tensile strength before exposure to soil. After 30 days of exposure, there was a decrease nearly $78 \%$ in the elastic modulus, indicating that degradation had occurred because, according to Nair and Thomas ${ }^{24}$, the hydrophilic nature of the cotton fibers can promote the onset of degradation of the composite. Thus, the observed decrease in the elastic modulus may be related to the reduced rigidity of the composite, which is caused by the absorption of water by the fibers and not by the actions of the microorganisms in the soil.

Figure 2 illustrates the surface morphology observed through SEM of the samples subjected to exposure in the simulated soil for 90 days. The images show no evidence of cavities, pores, colonies of microorganisms, biofilm formation or other surface defects that would be indicative

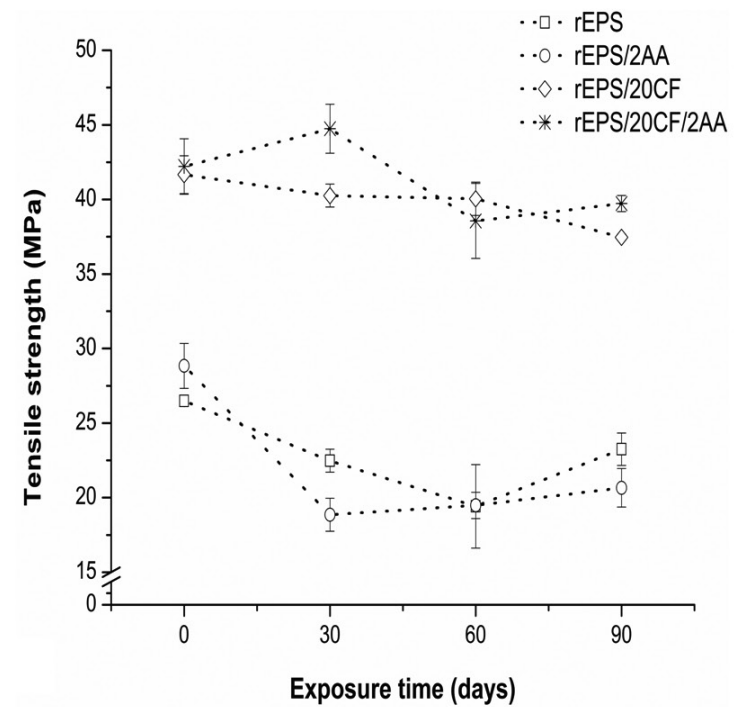

(a)

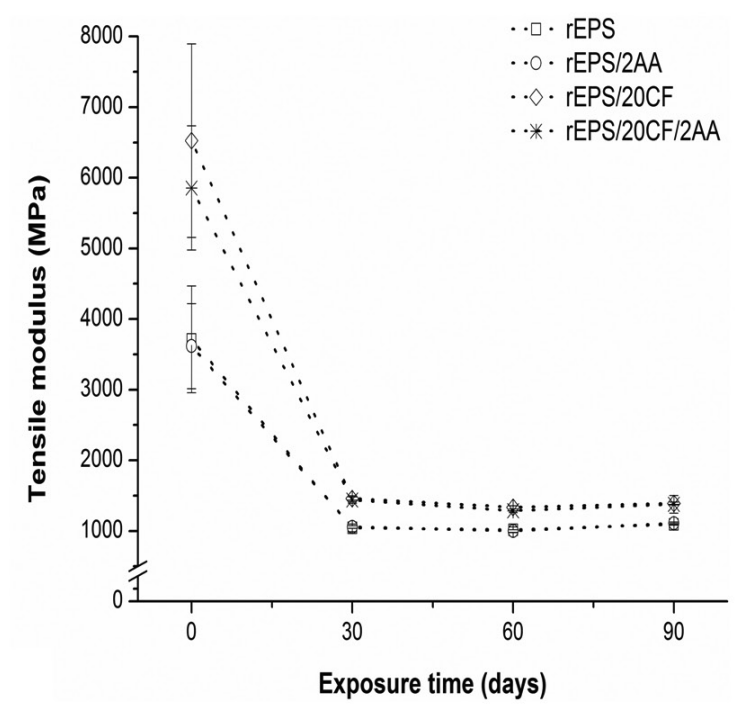

(b)

Figure 1. The measured mechanical properties of (a) tensile strength and (b) modulus of elasticity of the samples before and after exposure in the simulated soil. 

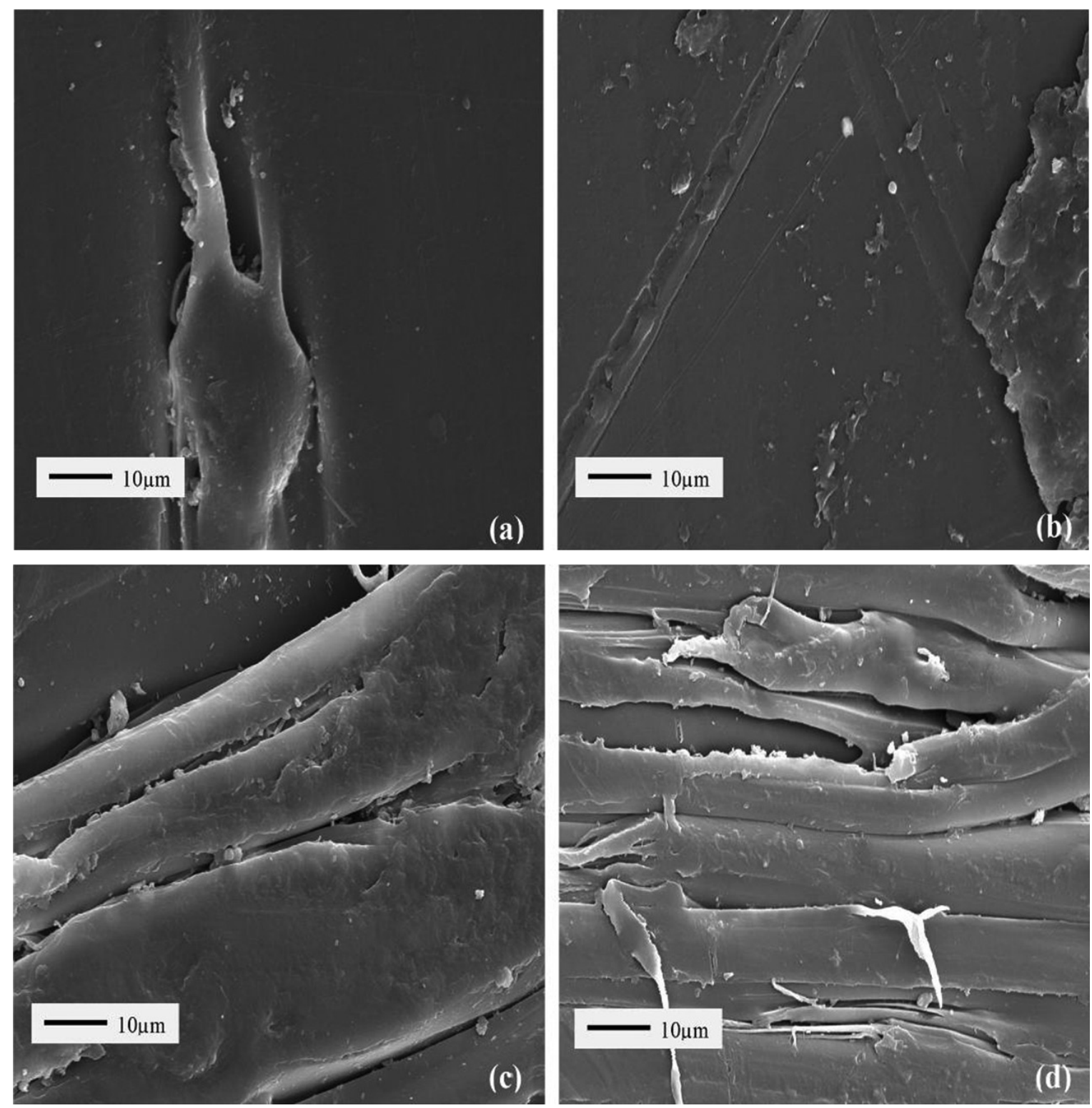

Figure 2. SEM micrograph of the sample surface after 90 days of exposure in the simulated soil: (a) rEPS, (b) rEPS/2AA, (c) rEPS/20CF and (d) rEPS/20CF/2AA.

of sample degradation caused by the microorganisms present in the medium ${ }^{25}$.

Figures 3 and 4 present the optical micrographs of the recycled matrix and cotton fiber composites, with or without the use of the coupling agent, before exposure and after 90 days of exposure in the simulated soil.

The surfaces of all of the samples after 90 days of exposure showed modifications, such as whitening and color change. Different microbiological secretions from certain microorganisms can produce distinct colors that are associated with specific types of microorganisms. According to Flemming ${ }^{26}$, the pigmentation observed in the material after the test in the simulated soil occurred due to the presence of certain species of fungi that produce secretions with different colors due to the nature of the polymer matrix.
Figure 5 presents the spectra of all of the different samples both before and after 90 days of exposure to the simulated soil.

The absorption bands for polystyrene are as follows: $3026 \mathrm{~cm}^{-1} \mathrm{C}-\mathrm{H}$ band related to the deformation of the aromatic ring; 2928 and $2851 \mathrm{~cm}^{-1}$ bands related to the asymmetric and symmetric stretching vibrations of $\mathrm{CH}_{2}$, respectively; 1600 and $1493 \mathrm{~cm}^{-1} \mathrm{C}-\mathrm{C}$ bands corresponding to the stretching of the aromatic ring; $1445 \mathrm{~cm}^{-1}$ band related to the bending vibration of $\mathrm{CH}_{2} ; 1069$ and $1028 \mathrm{~cm}^{-1} \mathrm{C}-\mathrm{H}$ bending vibrations of the ring plane; and 760 and $698 \mathrm{~cm}^{-1}$ $\mathrm{C}-\mathrm{H}$ bands that correspond to the deformation of the aromatic ring out of the plane ${ }^{27-30}$. No changes were observed in the polystyrene spectra after 90 days of exposure in the simulated soil. 

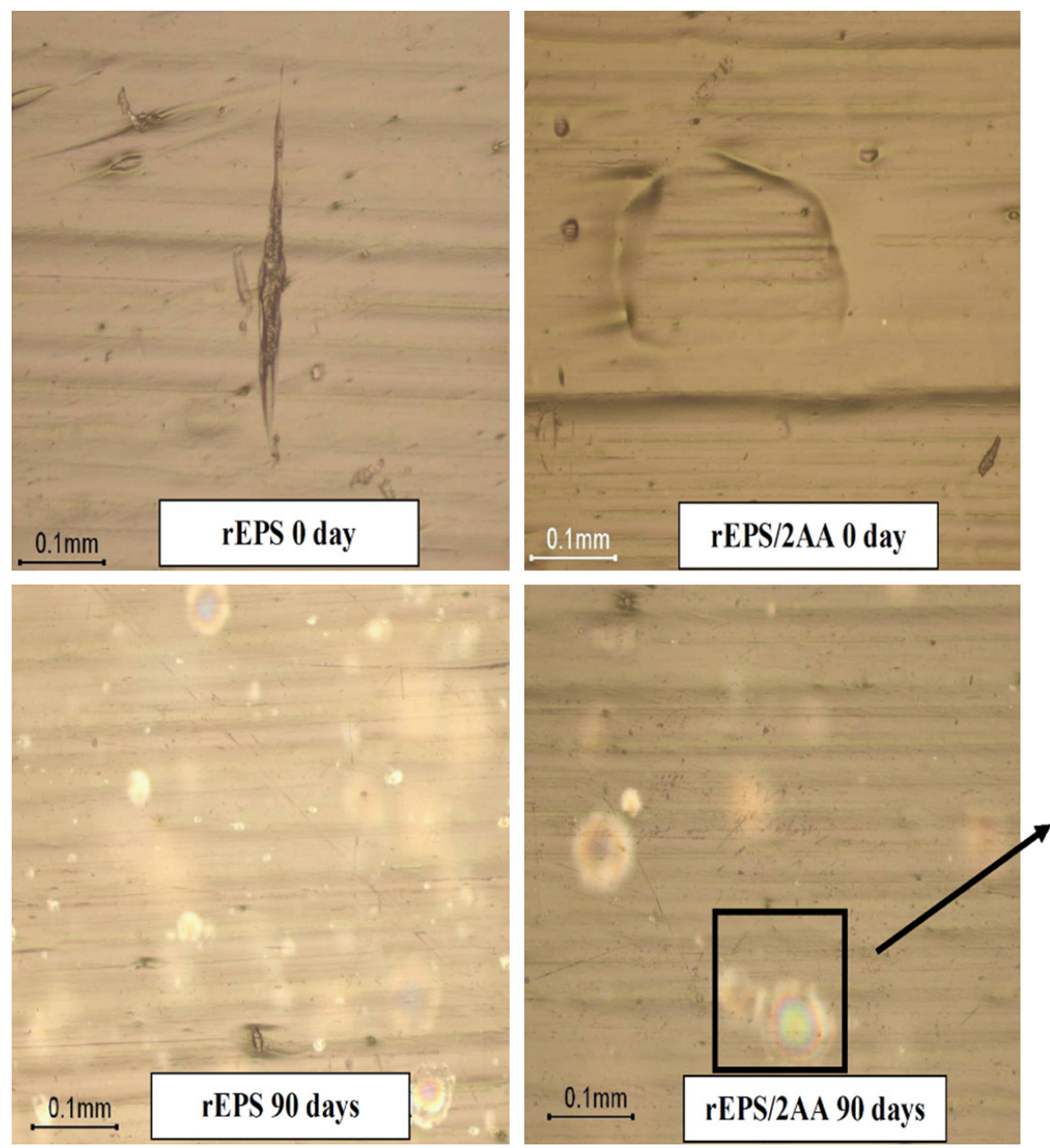

Figure 3. Optical micrographs of the surfaces of the samples without fiber before exposure (above) and after 90 days of exposure (below) to the simulated soil.

Table 2 presents the carbonyl index for all samples before and after 30, 60 and 90 days of exposure in the simulated soil. The carbonyl index was calculated as the ratio between the area of the band at $1744 \mathrm{~cm}^{-1}$ and the area of the band at $1600 \mathrm{~cm}^{-1}$ corresponding to the stretching of the $\mathrm{C}-\mathrm{H}$ bond of polystyrene.

The comparison of the carbonyl index for the samples before and after exposure shows an increase in the oxidation of samples with the fiber, which is possibly due to a relatively high exposure to oxygen of the matrix/fiber in the spaces that developed during processing. This behavior was also reported by Stark and Matuana ${ }^{31}$ in their evaluation of compounds developed with wood flour/HDPE.

During exposure to the simulated soil, chain scissions occurred; this was verified by observing the initial increase in the carbonyl index. Chain scissions may occur due to oxidation by dissolved oxygen in the soil. The carbonyl index decreases after longer exposures, which could be due to the consumption of the carbonyl groups by microorganisms and/or the formation of esters or the occurrence of the Norrish mechanism ${ }^{32,33}$. The presence of carbonyl groups, such as esters, carboxylic
Table 2. Carbonyl index of the samples before and after 30,60 and 90 days of exposure in the simulated soil.

\begin{tabular}{lcccc}
\hline \multirow{2}{*}{ Sample } & \multicolumn{4}{c}{ Carbonyl index } \\
\cline { 2 - 5 } & O days & 30 days & 60 days & 90 days \\
\hline rEPS & 0.1 & 0.6 & 0.3 & 0.1 \\
rEPS/2AA & 0.1 & 0.6 & 0.3 & 0.1 \\
rEPS/20CF & 0.4 & 0.5 & 0.4 & 0.5 \\
rEPS/20CF/2AA & 0.3 & 0.3 & 0.4 & 0.4 \\
\hline
\end{tabular}

acids, aldehydes and ketones, in a degraded polymer may indicate oxidation and that the material is more vulnerable to degradation ${ }^{34}$.

A significant change in the carbonyl index for rEPS/20CF and rEPS/20CF/2AA was not detected with exposure to the soil, and the oxidation promoted due to sample processing did not change with the exposure period. According to Schlemmer et al. ${ }^{35}$ the mechanisms involved in the biodegradation of PS are complex due to the processes of chain scission and oxidation caused by oxygen and microorganisms. 

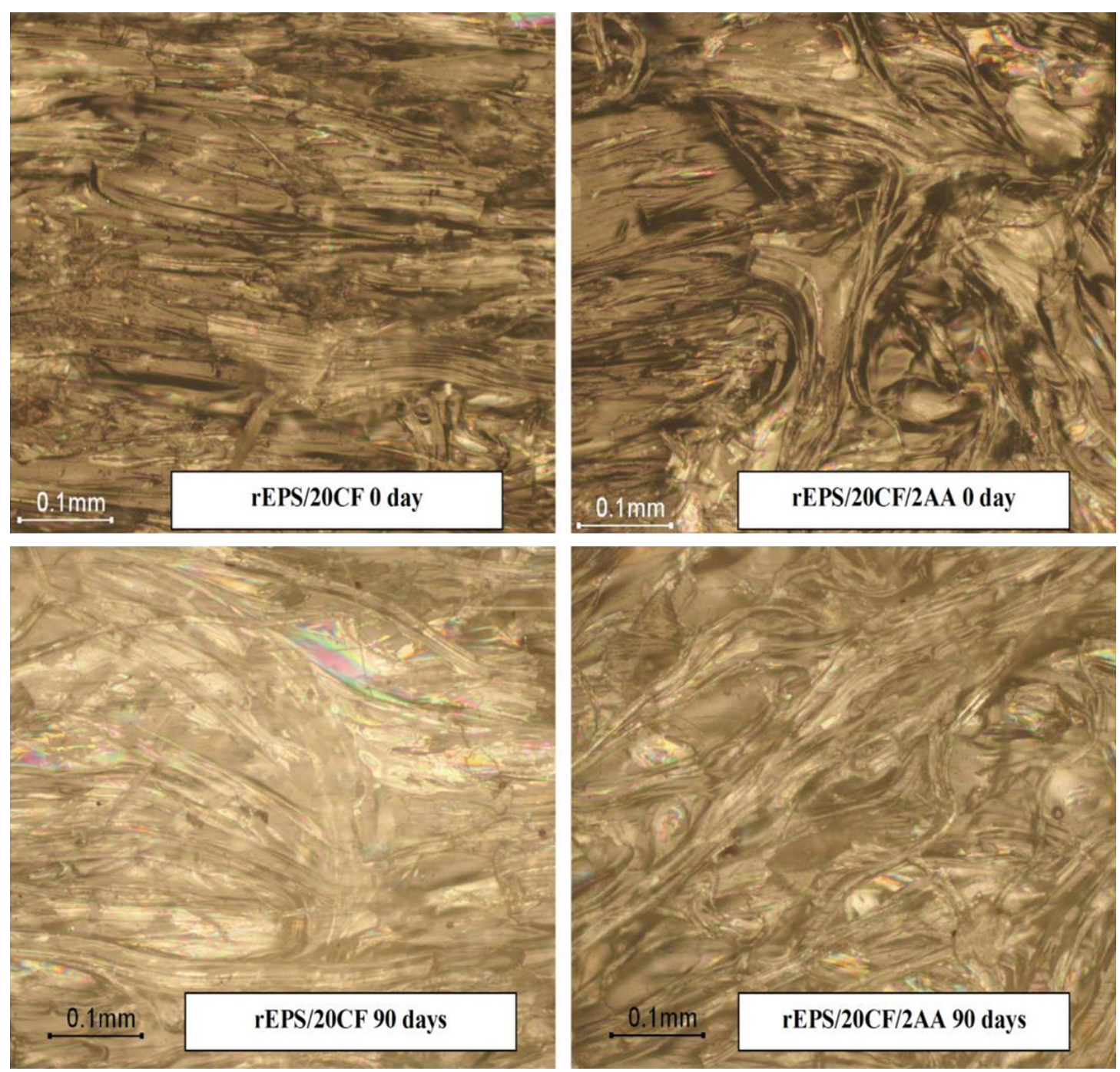

Figure 4. Optical micrographs of the surfaces of the composites before and after 90 days of exposure in the simulated soil.

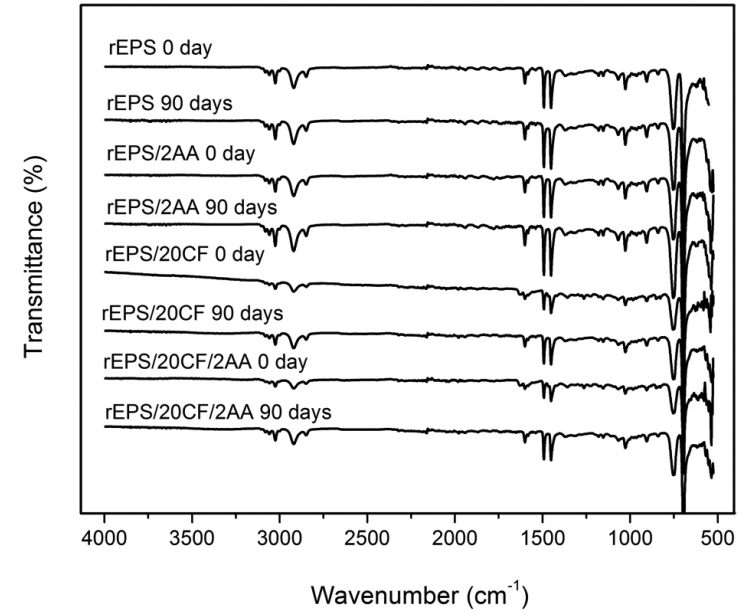

Figure 5. Spectra of the samples with and without the cotton fiber and the coupling agent before and after 90 days of exposure in the simulated soil.

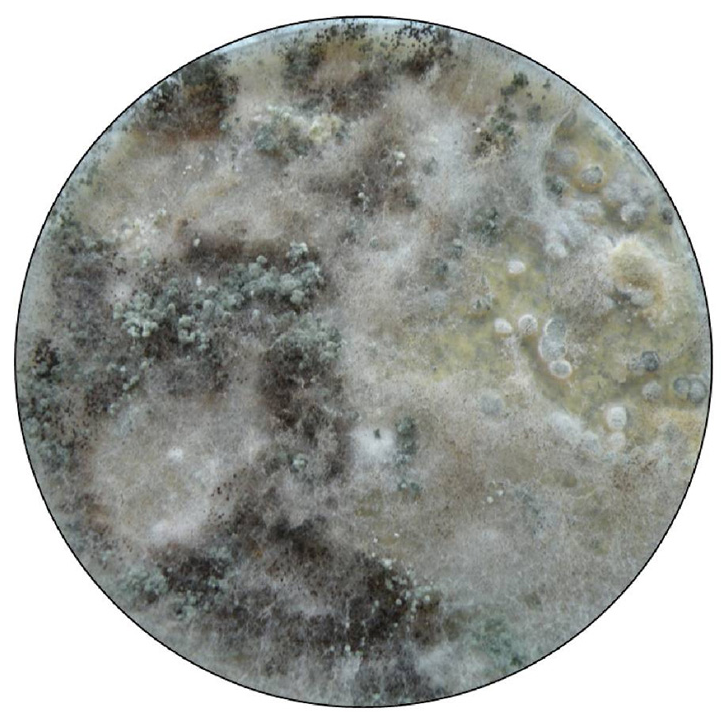

Figure 6. Photograph of the fungal colonies from the wash water of a sample after 90 days of exposure in the simulated soil. 
Fungal cultures were grown and observed from the wash water from all of the samples exposed to the simulated soil for periods of 30, 60 and 90 days. Figure 6 shows an example of the fungal cultures grown from the wash water of a sample after 90 days of exposure in the simulated soil.
Figure 7 shows a photograph of some of the fungi and larvae found in the wash water from all of the samples. The presence of nematode larvae, protozoa, spores and hyphae of fungi was observed in the wash water from all of the samples. Wash water from samples exposed for 30 and
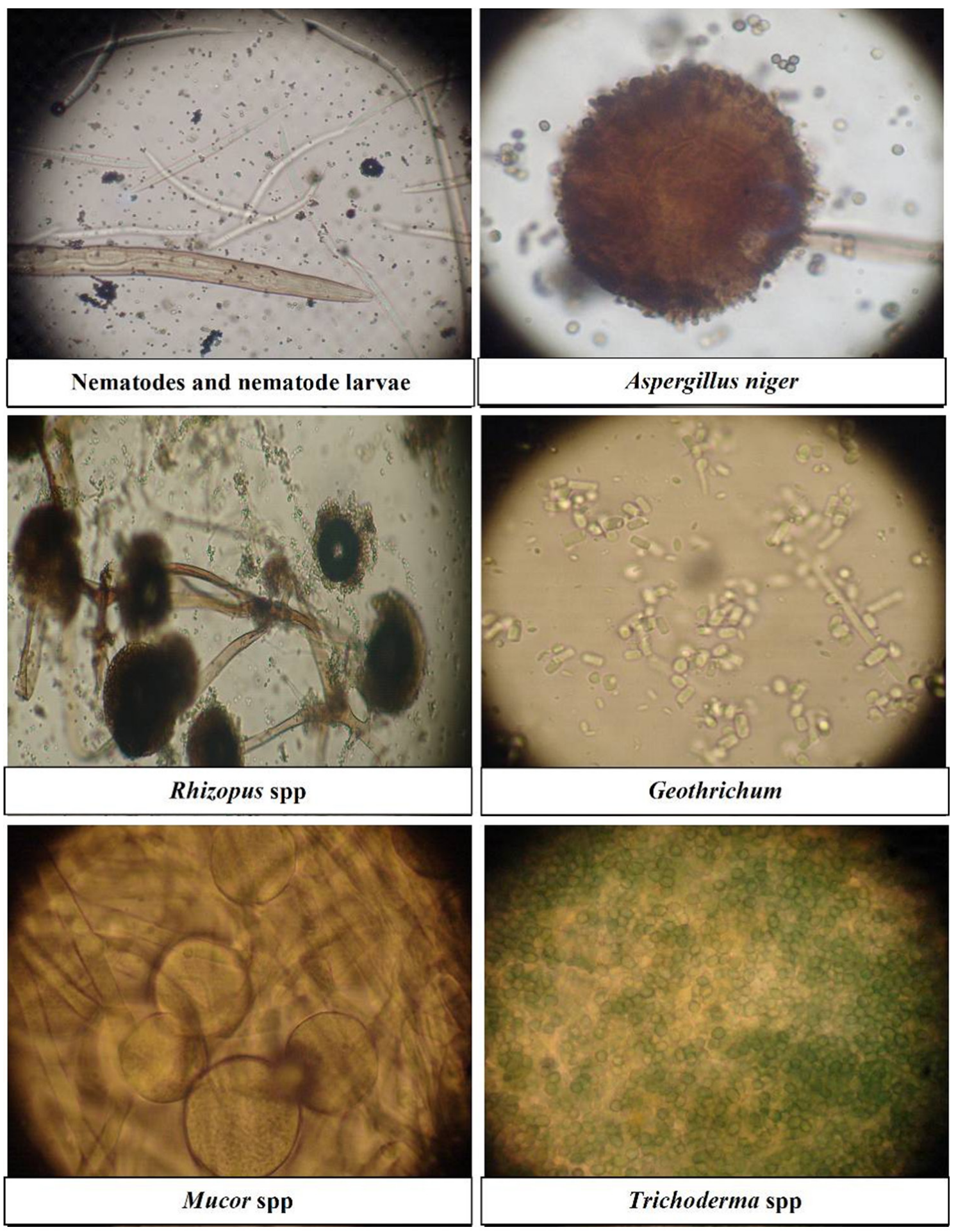

Figure 7. Photographs of the fungi identified in the cleaning water analysis. 
60 days possessed creamy white colonies of Geotrichum yeast, gray and white colonies of Rhizopus and Mucor spp, black colonies of Aspergillus niger, yellow-green colonies of Aspergillus flavus, green colonies of Aspergillus spp, and white filamentous colonies suggesting the presence of other bacteria. Wash water from samples exposed for 90 days in the simulated soil possessed green colonies of Aspergillus spp, gray and white colonies of Rhizopus spp, black colonies of Aspergillus niger, green colonies of Trichoderma spp and other unidentified bacteria.

\section{Conclusion}

The composites rEPS/20CF/2AA and rEPS/20CF presented superior mechanical properties compared to rEPS and $\mathrm{rEPS} / 2 \mathrm{AA}$, which can be attributed to the contribution of the cotton fibers in the composites.

The results of the evaluation behavior in simulated soil revealed a decrease in the mechanical properties of all tested materials. The tensile strength and the stiffness were reduced for all of the samples that were subjected to the same exposure period. However, the reduction of the stiffness was much more evident, which can be attributed to the interaction of water with the fibers in the composites. The presence of the cotton fibers and the coupling agents increased the evaluated mechanical properties.

\section{References}

1. Santos EF, Moresco M, Rosa SML and Nachtigall SMB. Extrusão de compósitos de PP com fibras curtas de coco: Efeito da temperatura e agente de acoplamento. Polímeros. 2010; 20:215220. http://dx.doi.org/10.1590/S0104-14282010005000036

2. Santos PA, Spinacé MAS, Fermoselli KKG and De Paoli MA. Polyamide-6/vegetal fiber composite prepared by extrusion and injection molding. Composites Part. A. 2007; 38:2404-2411. http://dx.doi.org/10.1016/j.compositesa.2007.08.011

3. Araujo JR, Mano B, Teixeira GM, Spinacé MAS and De Paoli MA. Biomicrofibrilar composites of high density polyethylene reinforced with curaua fibers: Mechanical, interfacial and morphological properties. Composites Science and Technology. 2010; 70:1637-1644. http://dx.doi.org/10.1016/j. compscitech.2010.06.006

4. Corradini E, Ito EN, Marconcini JM, Rios CT, Agnelli JAM and Mattoso LHC. Interfacial behavior of composites of recycled poly(ethyelene terephthalate) and sugarcane bagasse fiber. PolymerTesting. 2009; 28:183-187. http://dx.doi.org/10.1016/j. polymertesting.2008.11.014

5. Machado MLC, Pereira NC, Miranda LF, Terence MC and Pradella JGC. Estudo das Propriedades Mecânicas e Térmicas do Polímero Poli-3-Hidroxibutirato (PHB) e de Compósitos PHB/Pó de Madeira. Polímeros. 2010; 20:65-71. http://dx.doi. org/10.1590/S0104-14282010005000011

6. Garcia M, Garmendia I and Garcia J. Influence of natural fiber type in eco-composites. Journal of Applied Polymer Science. 2008; 107:2994-3004. http://dx.doi.org/10.1002/ app. 27519

7. Coutinho FMB and Costa THS. Performance of polypropylenewood fiber composites. Polymer Testing. 1999; 18:581-587. http://dx.doi.org/10.1016/S0142-9418(98)00056-7

8. Bourmaud A and Baley C. Investigations on the recycling of hemp and sisal fibre reinforced polypropylene composites.
The increase in the carbonyl index after 30 days of exposure in soil is associated with the degradation of the polymer, which results in the formation of carbonyl groups. With increased exposure times, the carbonyl index decreased as a result of the actions of microorganisms. No appreciable difference in the degradation process was observed regarding to the presence of the coupling agent or cotton fibers.

No biofilm formation was observed on the surfaces of the samples, but changes in the color of the surfaces after 90 days of exposure due to the colonization of the surface by bacteria and fungi were observed.

Changes in the properties of the composites were observed after exposure in simulated soil however no sign of biodegradation, which should be related to the relatively short time of exposure.

\section{Acknowledgements}

The authors acknowledge CNPq and FAPERGS for granting scholarships and UCS and the City Hall of Caxias do Sul for financial support. The authors would also like to acknowledge The Association of Recyclers of Caxias do Sul for donating the postconsumer polystyrene, the Sartomer Company for donating the coupling agent and ITM for donating the cotton waste materials necessary to conduct this study.

Polymer Degradation and Stability. 2007; 92:1034-1045. http:// dx.doi.org/10.1016/j.polymdegradstab.2007.02.018

9. Manikandan NKC, Sabu T. Effect of interface modification on the mechanical properties of polystyrene-sisal fiber composites. Polymer Composites. 2003; 24:332-342. http:// dx.doi.org/10.1002/pc.10033

10. Manikandan NKC, Diwan ZSM and Sabu T. Tensile Properties of Short Sisal Fiber Reinforced Polystyrene Composites. Journal of Applied Polymer Science. 1996; 60:1483-1497. http://dx.doi. org/10.1002/(SICI)1097-4628(19960531)60:9<1483::AIDAPP23>3.0.CO;2-1

11. Pracella M, Chionna D, Anguillesi I, Kulinski Z and Piorkowska E. Functionalization, compatibilization and properties of polypropylene composites with Hemp fibres. Journal of Applied Polymer Science. 2006; 66:2218-2230.

12. Harnnecker F, Rosa DS and Lenz DM. Biodegradable Polyester-Based Blend Reinforced with Curaua Fiber: Thermal, Mechanical and Biodegradation Behaviour. Journal of Polymer Environment. 2012; 20:237-244. http://dx.doi.org/10.1007/ s10924-011-0382-5

13. Stromberg E and Karlsson S. The effect of biodegradation on surface and bulk property changes of polypropylene, recycled polypropylene and polylactide biocomposites. International Biodeterioration and Biodegradation. 2009; 63:1045-1053. http://dx.doi.org/10.1016/j.ibiod.2009.08.003

14. Borsoi C, Scienza LC and Zattera AJ. Characterization of Composites Based on Recycled Expanded Polystyrene Reinforced with Curaua Fibers. Journal of Applied Polymer Science. 2012; 128:653-659. http://dx.doi.org/10.1002/ app.38236

15. American Society for Testing and Material Standards - ASTM. ASTM G160: Standard Practice for Evaluating Microbial 
Susceptibility of Nonmetalic Materials by Laboratory Soil Burial. ASTM; 2003.

16. American Society for Testing and Material Standards - ASTM. ASTM D638: Standard Test Method for Tensile Properties of Plastics. ASTM; 2010.

17. Vilaplana F, Ribes-Greus A and Karlsson S. Degradation of recycled high-impact polystyrene. Simulation by reprocessing and thermo-oxidation. Polymer Degradation and Stability. 2006; 91:2163-2170. http://dx.doi.org/10.1016/j. polymdegradstab.2006.01.007

18. Brandalise DL, Ribeiro AP and Pinheiro LA. Estudo Do Comportamento Termo-Oxidativo Do Poliestireno Reprocessado. In: Anais do 10th Congresso Brasileiro De Polímeros - CBPol; 2009; Foz do Iguaçu. ABPol; 2009.

19. Borsoi C, Angrizani CC, Scienza LC and Zattera AJ. Obtenção e caracterização de compósitos utilizando poliestireno como matriz e resíduos de fibras de algodão da indústria têxtil como reforço. Polímeros. 2011; 21:271-279. http://dx.doi. org/10.1590/S0104-14282011005000055

20. De Paoli MA. Degradação e Estabilização de Polímeros. 2. versão on-line. 2008.

21. Araujo JR, Waldman WR and De Paoli MA. Thermal properties of hight density polythylene composites with natural fiber: Coupling agent effect. Polymer Degradation and Stability. 2008; 93:1770-1775. http://dx.doi.org/10.1016/j. polymdegradstab.2008.07.021

22. Bledzki AK and Gassan J. Composites reinforced with cellulose based fibers. Progress in Polymer Science. 1999; 24:221-274. http://dx.doi.org/10.1016/S0079-6700(98)00018-5

23. Joseph PV, Rabello MS, Mattoso LHC, Joseph K and Thomas S. Environmental effects on the degradation behaviour of sisal fibre reinforced polypropylene composites. Journal of Applied Polymer Science. 2002; 62:1357-1372.

24. Nair KCM and Thomas S. Effect of Ageing on the Mechanical Properties of Short Sisal Fibre Reinforced Polystyrene Composites. Journal of Thermoplastic Composites. 2003; 16:248-27.

25. Gu JD. Microbiological deterioration and degradation of synthetic polymeric materials: recent research advances. International Biodeterioration and Biodegradation. 2003; 52:69-91. http:// dx.doi.org/10.1016/S0964-8305(02)00177-4

26. Flemming HC. Relevance of biofilms for the biodeterioration of surfaces of polymeric materials. Polymer Degradation and Stability. 1998; 59:309-315. http://dx.doi.org/10.1016/S01413910(97)00189-4
27. Chauhan RS, Gopinath S, Razdan P, Delattre C, Nirmala GS and Natarajan R. Thermal decomposition of expanded polystyrene in a pebble bed reactor to get higher liquid fraction yield at low temperatures. Waste Management. 2008; 28:21402145. PMid:18032014. http://dx.doi.org/10.1016/j. wasman.2007.10.001

28. Mielczarski JA, Jeyachandran YL, Mielczarski E and Rai B. Modification of polystyrene surface in aqueous solutions. Journal of Colloid and Interface Science. 2011; 362:532-539. PMid:21802090. http://dx.doi.org/10.1016/j.jcis.2011.05.068

29. Patole AS, Patole SP, Jung S-Y, Yoo J-B, An J-H and Kim T-H. Macromolecular Nanotechnology. Self assembled graphene/carbon nanotube/polystyrene hybrid nanocomposite by in situ microemulsion polymerization. Europe Polymer Journal. 2012; 48:252-259. http://dx.doi.org/10.1016/j. eurpolymj.2011.11.005

30. Riyajana S-A, Intharit I and Tangboriboonrat P. Physical properties of polymer composite: Natural rubber glove waste/polystyrene foam waste/cellulose. Industrial Crops and Products. 2012; 36:376-382. http://dx.doi.org/10.1016/j. indcrop.2011.10.017

31. Stark NM and Matuana LM. Surface chemistry changes of weathered HDPE/wood-flour composites studied by XPS and FTIR spectroscopy. Polymer Degradation and Stability. 2004; 86:1-9. http://dx.doi.org/10.1016/j. polymdegradstab.2003.11.002

32. Sudhakar M, Doble M, Murthy PS and Venkatesan R. Marine microbe-mediated biodegradation of low- and highdensity polyethylenes. International Biodeterioration and Biodegradation. 2008; 61:203-213. http://dx.doi.org/10.1016/j. ibiod.2007.07.011

33. Konduri MKR, Koteswarareddy G, Kumar DBR, Reddy BV and Narasu ML. Effect of Pro-Oxidants on Biodegradation of Polyethylene (LDPE) by Indigenous Fungal Isolate, Aspergillus oryzae. Journal of Applied Polymer Science. 2011; 120:35363545. http://dx.doi.org/10.1002/app.33517

34. Gulmine JV, Janissek PR, Heise HM and Akcelrud L. Degradation profile of polyethylene after artificial accelerated weathering. Polymer Degradation and Stability. 2003; 79:385397. http://dx.doi.org/10.1016/S0141-3910(02)00338-5

35. Schlemmer D, Sales MJA and Resck IS. Preparação, Caracterização e Degradação de Blendas PS/TPS Usando Glicerol e Óleo de Buriti como Plastificantes. Polímeros. 2010; 20:6-13. http://dx.doi.org/10.1590/S010414282010005000002 